\title{
III. A letter to Professor Airy, in reply to his remarks on some passages in a paper by Mr. Ivory
}

\author{
J. Ivory Esq. M.A. F.R.S.
}

To cite this article: J. Ivory Esq. M.A. F.R.S. (1827) III. A letter to Professor Airy, in reply to his remarks on some passages in a paper by Mr. Ivory, Philosophical Magazine Series 2, 2:7, 16-20, DOI: $10.1080 / 14786442708675612$

To link to this article: http://dx.doi.org/10.1080/14786442708675612

册 Published online: 10 Jul 2009.

Submit your article to this journal $₫$

Џll Article views: 1

Q View related articles $₫$ 
sance des tems pour l'année 1826. A'cette occasion, j'ai relu ce Mémoire et un autre qui en est le développement (Annales de Physique et de Chimie, tome xxiii. page 337); et j'avoue qué je n'y ai rien trouvé d'inexact. $\mathrm{Mr}$. Ivory en comparant la formule (6) de mon Mémoire à une équatiòn qu'il a trquvée d'une autre manière, pense qu'elles sont différentés l'une de l'autre, et que c'est la mienne qui est en défaut. J'attend'rai qu'il fasse voir en quoi le raisonnement quí m'a conduil à cette formule seroit erronné ou incomplet; et jusques-là je persisterai à croire qu'elle exprime la variation de température qui accompágne une très petite compression ou dilatation de l'air, quand sa: quantité de chaleur propre reste la même, ainsi qu'on le suppose dans le phénomène du son, à cause dé la rapidité des vibrations du fluide; ou bien encore, comme cela!a liea lorsque l'air est comprimé dàns un vase fermé dont la matière n'absorbe pas sensiblement la chaleur.

Paris, le 19 Mai 1827.

Poissan.

III. A Letter to Professor Airy, in reply to his Remarks on some Passages in a Paper by Mr. Ivory. By J. Ivory, Esq. M.A. F.R.S.

To the Editors of the Philosophical Magazine and Annals.

Gentlemen,

I HAVE to beg the favour of you to insert in your next publication the following short letter occasioned by Professor Airy's remarks in your last.

To G. B. Airy, Esq. A.M., Lucasian Professor of MathemaSir, tics in the University of Cambridge.

I have examined the note in your paper in the Phil. Trans. 1826, but I confess, without seeing much reason to alter my opinion. In my paper to which the note refers, I limited my investigation to homogeneous fluids, expressly setting aside those of variable density as matter for future discussion. Your paper is confined to the case of variable density, and your reference to a law restricted to homogeneous fluids appears inconsiderate and misplaced, and looks as if you had gone out of your way to find fault with what I had written. I do not conceive that Science could in any respect be bettered by the note, and ultimately it will be found that no advantage has resulted from it. You barely assert an opinion without condescending to allege any reason on which it is founded, and I am not aware that such a procedure is very unaptly charac- 
terized by the terms I have used. I should be sorry to be found a great trespasser on this occasion; but, for many years, I have been very frequently attacked without rhyme or reason, and with no regard to scruples: and this will, I hope, be deemed a sufficient apology for any warmth of language, more especially to a gentleman who, it appears from his paper, knows full well to do himself justice.

What I read in the last Phil. Mag., p. 447, induced me to examine my investigation in the preceding Number, pp. 327, 328 ; and $I$ find that $I$ have drawn a wrong inference from my analysis. The evanescent fractions $\frac{k}{g}, \frac{k}{g}(h, k, g$ all vanish together with $f$ ) are in every case equal to zero; so that my reasoning is entirely favourable to M. Poisson's proposition. As my investigation is free from precarious assumptions, $\mathbf{l}$ will briefly state the steps of it, referring to the place cited for an explanation of the symbols. We have,

consequently,

$$
y^{\prime}=y+\mathrm{A} h+\mathrm{B} k
$$

$$
\frac{1}{2 \pi} \int \frac{g y^{\prime} d s}{f^{3}}=\frac{1}{2 \pi} \int \frac{g y d s}{f^{3}}+\frac{1}{2 \pi} \int \frac{g(\mathrm{~A} h+\mathrm{B} k) d s}{f^{3}} .
$$

Now, $d s=\sin \theta^{\prime} d \theta^{\prime} d \psi^{\prime}=\sin \theta d h d k$; and, the value of $d s$ being substituted, the second term on the right hand integrated as at the place cited, is always equal to zero; so that we have

$$
\frac{1}{2 \pi} \int \frac{g y^{\prime} d s}{f^{3}}=\frac{y}{2 \pi} \int \frac{g d s}{f^{3}}=y \text {. }
$$

Admitting therefore that the proposition is proved in the most general sense, let us examine the consequence.

The development is likewise proved in the most general sense. For there is no objection to the process by which the following formula is deduced from the general theorem, viz.

$$
4 \alpha \pi a^{2} y=\frac{\mathrm{U}(0)}{a}+\frac{3 \mathrm{U}(1)}{a^{2}}+\frac{5 \mathrm{U}(2)}{a^{3}}+\& c \text {. }
$$

Now this is the development. For we have,

$$
\mathrm{U}^{(i)}=\alpha a^{i+3} \int y^{l} d \varpi^{\prime} d \theta^{\prime} \sin \theta^{\prime} \mathrm{Q}^{(i)} ;
$$

and as $Q^{(i)}$ is a function of $\mu, \sqrt{1-\mu^{2}} \cdot \cos \omega, \sqrt{1-\mu^{\bar{z}}} \cdot \sin \omega$, it is plain that $U^{(i)}$ will be a like function, the coefficients alone being changed by the integrations. The development may always be found, namely, by performing the requisite integrations for every term. We must admit too that it is unique; for every term is a definite integral, involving nothing pre-

New Series. Vol. 2. No. 7. July 1827. D carious 
carious and contained between given limits. I conclude, therefore, that on the grounds we now go upon, we have,

$$
y=\mathrm{Y}^{(0)}+\mathrm{Y}^{(1)}+\mathrm{Y}^{(3)}+\& \mathrm{c}
$$

with all the generality that Laplace and Poisson have asserted.

Supposing that $\alpha$ is less than unit, let us expand the integral expression, thus *,

$$
\frac{1}{4 \pi} \int \frac{\left(1-x^{2}\right) y^{\prime} d s}{f^{3}}=\mathrm{Y}\left({ }^{0}\right)+\alpha \mathrm{Y}(1)+\alpha^{2} . \mathrm{Y}\left({ }^{2}\right)+\& \mathrm{c} .
$$

Here there is numerical equality between the finite expression on one side and the infinite series on the other: for, a being léss than unit, the terms of the series continually decrease and finally become insensible. But, when $\alpha=1$, the principle by which the equality was before proved disappears, and we can no longer affirm that there is an equation. If we suppose a to become ever so little greater than unit, there is a disruption of the continuity, the quantity on one side becoming negative, and the series, on the other side infinitely great. In many cases it is certain that the series, in the circumstances mentioned, is absurd and insignificant in respect of numerical value. How are we to separate such cases from those in which the analysis may be employed as a legitimate means of investigation? It may be argued that the theorem alone is not sufficient; because, in the demonstration the quantity $y$ is considered as finite; and some check in respect of numerical quantity is always requisite when a finite is changed into an infinite expression. How comes it that a series, which is interminable, and in which no principle of convergency has been pointed out, nevertheless represents a finite quantity with numerical exactness?

Suppose that $y$ is a rational function of $\cos \theta, \sin \theta, \cos \omega$, $\sin \omega$, or of $\mu, \sqrt{1-\mu^{2}}, \cos \omega, \sin \omega$; and put,

$$
\begin{aligned}
t=\sqrt{1-\mu^{2}} \cdot \cos \omega, \quad s=\sqrt{1-\mu^{3}} \cdot \sin \omega ; & \\
\text { then } \quad \cos \omega & =\frac{t}{\sqrt{1-\mu^{2}}}, \quad \sin \omega=\frac{s}{\sqrt{1-\mu^{2}}} .
\end{aligned}
$$

By substituting these values it is evident that $y$ will be converted into a function of $\mu, s, t$; and, by expanding the radicals wherever they occur, it will be changed into an infinite expression which is a rational function of $\mu, s, t$. This expression is unique; for the algebraic operations can be performed only one way. We have now two infinite expressions of $y$ in terms of the same quantities $\mu, s, t$; namely, that (A)

* Comn. des Tems 1829, p. 333. 
resulting from Laplace's development, and that obtained by the algebraic process. Each of these expressions is obtained in a manner that is unique: there is nothing uncertain in either; and it must be admitted that they are identical. Taken in toto, they both consist of the same simple quantities connected with the same signs; but in one, these quantities are distributed in groups possessed of a general property; and in the other, there is no artificial arrangement. If one be numerically equal to the finite quantity $y$ the other must be so too; and if the first may be substituted for $y$ in any investigation, so likewise may the second.

It is evident that the radicals expanded in the algebraic value of $y$ produce, converging serieses only; and that, by extending the portions of the serieses taken in, we may approximate to the value of $y$ indefinitely. When $\mu= \pm 1$, the approximation is not disturbed by that part arising from the expansion of $\sqrt{1-\mu^{2}}$ and its powers; and the part produced by $\frac{1}{\sqrt{1-\mu^{2}}}$ and its powers, which might be infinitely great, vanishes, because every term is multiplied by $s, t$ which are equal to zero when $\mu= \pm 1$. Thus the approximation holds good for all values of $\mu$ between the limits \pm 1 . I therefore conclude generally that every function of two arcs, which is always finite between the prescribed limits, may be changed into a finite and rational function of three coordinates of a sphere, that shall approximate in any required degree to the given function.

There is no difficulty attending this analysis when $y$ is accurately a finite and rational function of three coordinates of a sphere; and we may certainly comprehend in the same conclusion all cases in which we can approximate indefinitely to the value of $y$ by expressions of the same kind. We thus obtain the theory in all its generality, and we place it on its right basis, which is the nature of the development.

I have never found fault with the demonstrations of the theorem, except on just grounds. In the Mécanique Céleste, livr. ii. No. 10, the thickness of the molecule at the attracted point is not considered; which occasions a difficulty of which Lagrange has treated: and in livr. xii. the same thickness is made ultimately divisible by the square of its distance from the attracted point; which would limit the analysis to a very particular class of functions. The demonstration of M. Poisson amounts only to this,

$$
y=\frac{y}{2 \pi} \int \frac{\left(1-\alpha^{2}\right) d s}{f^{3}},
$$

which seems an identical proposition, the quantity into which D 2 
$y$ is multiplied on the right-hand side, being equal to unit. But the theorem alone, without considering the nature of the development, cannot be a proper foundation for this doctrine; it does not put the analyst in possession of the true principles of the method. All the difficulties, and, I may add, a great part of the celebrity of this kind of investigation, have arisen from the manner in which it has been presented to the public.

I have no room left to add any thing respecting the equilibrium of fluids. From what you say, 1 apprebend there is not much between us. . It would greatly contribute to throw light on this subject if any one would attempt to demonstrate synthetically Laplace's proposition, namely, That a homogeneous planet in a fluid state, will be in equilibrio, when the resultant of the accelerating forces acting upon a particle in the surface is perpendicular to that surface. I am of opinion he would be forced to adopt my conditions of equilibrium, in which case the task is easy; but I maintain that it is impossible he could prove any thing contrary to them. I have the honour to be, sir, Your obedient servant,

June 12, 1827 .

J. IVORY.

IV. On Exceptions to the Law that Salts are more soluble in hot than in cold Water; with a new Instance. By Thomas Graham, M.A.*

THE bodies which have been observed to possess this anomalous solubility are the hydrate of lime and the sulphate of soda : its detection in the first case we owe to Mr. Dalton, and in the latter to M. Gay-Lussac. The phosphate of magnesia, a body like the hydrate of lime of sparing solubility, appears from our experiments to belong to the same class.

To form phosphate of magnesia, phosphate of soda and sulphate of magnesia in crystals were separately dissolved in water, in the proportion of 21 parts of the former to 15.375 parts of the latter, or of an integrant particle of each. These solutions were mixed and set aside. Within twenty-four hours the phosphate of magnesia had precipitated, generally in tufts of short acicular crystals, while sulphate of soda remained in solution. According to Dr. Thomson this salt is composed of One atom phosphoric acid . . . 3.5

One atom magnesia . . . . . 2.5

Seven atoms water $\ldots \ldots \ldots .7 \cdot 875$

$13 \cdot 875$

* Communicated by the Author. 